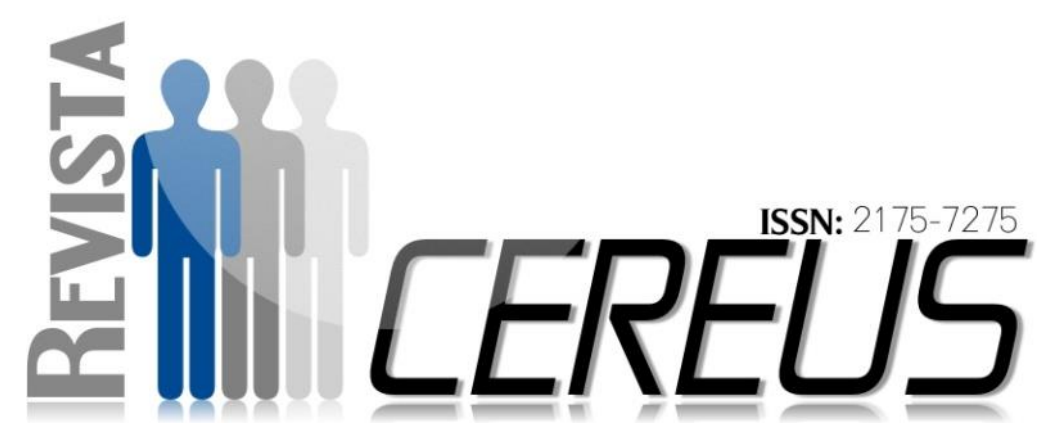

\title{
AVALIAÇÃO DA ADEQUAÇÃO NUTRICIONAL DA ALIMENTAÇÃO ESCOLAR OFERTADA EM UMA ESCOLA DE TEMPO INTEGRAL DO MUNICÍPIO DE PALMAS, TOCANTINS, BRASIL
}

\section{LUCENA, Ananda Lays Nunes ${ }^{1}$ \\ BEZERRA, Mírian da Silva ${ }^{1}$ \\ CARDOSO, Lia Raquel Chaves ${ }^{1}$ \\ SILVA, Kellen Cristine ${ }^{2}$ \\ PINTO, Sônia Lopes²}

\section{RESUMO}

Objetivo: Analisar a adequação da alimentação fornecida por uma escola de tempo integral, para diferentes faixas etárias, de acordo com as recomendações do Programa Nacional de Alimentação Escolar (PNAE). Método: Adotou-se a pesagem direta para se obter a disponibilidade dos alimentos oferecidos no desjejum, almoço e lanche da tarde, durante dez dias consecutivos. A avaliação da adequação nutricional foi realizada segundo o PNAE para macronutrientes e micronutrientes e fibras. A adequação dos nutrientes foi avaliada para as faixas etárias de 6-10, 11-15 e 16-18 anos, conforme perfil dos estudantes da escola. Para avaliação dos cardápios utilizou-se o programa software Avanutriß. Também foi avaliado se o cardápio elaborado correspondia 
ao cardápio executado pela Secretaria de Educação. Resultados: Dos dez avaliados, apenas 1 dia não houve mudanças no cardápio elaborado. Para a faixa etária de 6 a 10 anos, observou-se adequação dos $70 \%$ recomendados para a energia, carboidrato, proteína, vitamina $A, C$, zinco e ferro. Na faixa etária de 11-15anos, houve adequação apenas do ferro, vitamina $A$ e $C$. Já para os estudantes de 16-18 anos apenas a vitamina A e C adequaram-se conforme a recomendação. Observou-se que a fibra alimentar não atingiu a recomendação para nenhuma faixa etária, assim como o lipídio, cálcio e magnésio. Conclusão: Os resultados mostram necessidade de corrigir falhas do conteúdo nutricional das refeições ofertadas, pois constituem parte fundamental do consumo alimentar dos alunos de escolas de tempo integral.

Palavras chave: Alimentação escolar. Planejamento do cardápio. Infância. Adolescência.

\section{EVALUATION OF NUTRITIONAL ADEQUACY OF SCHOOL FEEDING OFFERED AT A COMPREHENSIVE TIME SCHOOL IN PALMAS CITY, TOCANTINS, BRAZIL}

\section{ABSTRACT}

Objective: To analyze the adequacy of feeding provided by a full-time school for different age groups, according to the recommendations of the National School Feeding Program (PNAE). Method: Direct weighing was used to obtain the availability of food offered for breakfast, lunch and afternoon snack for ten consecutive days. The nutritional adequacy assessment was performed according to the PNAE for macronutrients and micronutrients and fibers. The adequacy of the nutrients was evaluated for the age groups of $6-10,11$ 15 and 16-18 years, according to the profile of the students of 
the school. For the evaluation of the menus, the software Avanutriß was used. It was also evaluated if the menu elaborated corresponded to the menu executed by the Education Department. Results: Of the ten evaluated, only 1 day there were no changes in the elaborated menu. For the age group of 6 to 10 years, the recommended $70 \%$ for energy, carbohydrate, protein, vitamin A, C, zinc and iron were adequate. In the age group of 11-15 years, only iron, vitamin A and $C$ were adequate. Already for students aged 16-18, vitamin $\mathrm{A}$ and vitamin $\mathrm{C}$ were adequate as recommended. It was observed that dietary fiber did not reach the recommendation for any age group, as did lipid, calcium and magnesium. Conclusion: The results show a need to correct deficiencies in the nutritional content of the meals offered, since they constitute a fundamental part of the food consumption of students of full-time schools.

Keywords: School feeding. Menu planning. Childhood. Adolescence. 


\section{INTRODUÇÃO}

$\mathrm{Na}$ fase escolar as crianças apresentam necessidades nutricionais mais elevadas, bem como maior interesse, preferências pelos alimentos, capacidade de seleção e também a escolha da quantidade que desejam comer (BRASIL, 2012). Neste contexto, surgem as práticas alimentares inadequadas, que é um agravante para a saúde, e, quando consolidados nos primeiros anos de vida, podem causar implicações metabólicas imediatas e potencializar o risco de obesidade assim como doenças crônicas na vida adulta (PÉREZ-CUETO et al, 2009).

Com o intuito de minimizar esta situação preocupante, deve-se promover quanto antes, ações de educação alimentar e nutricional para incentivar os hábitos alimentares saudáveis (MENEGAZZO et al, 2011). $O$ ambiente escolar é fundamental para a determinação desses hábitos, visto que a criança permanece no local durante um ou dois períodos do dia, convivendo com educadores, cuidadores e com outras crianças que irão auxiliar e influenciar na formação de seus valores e de seu estilo de vida, entre eles a alimentação (SBP, 2008).

Nesse sentido, o Programa Nacional de Alimentação Escolar (PNAE) se faz importante, por meio de distribuição de refeições durante os intervalos das atividades escolares. $O$ PNAE tem por objetivo, contribuir para o crescimento, o desenvolvimento biopsicossocial, o crescimento intelectual e a formação de práticas alimentares saudáveis dos alunos, por meio da oferta de refeições que supram suas necessidades nutricionais, baseadas nas Dietary Reference Intake (DRI), durante o período letivo (BRASIL, 2013). Um dos objetivos do programa para escolas de tempo integral e Programa Mais Educação é a elaboração de cardápios que supram $70 \%$ das necessidades nutricionais, distribuídas em, no mínimo, três refeições, assim atendendo às necessidades dos alunos com a maior jornada diária de aula (BRASIL 2013).

Danelon et al (2006) afirma que, com a ampliação da jornada de aula diária, percebe-se a necessidade de reavaliação da alimentação oferecida, com vistas a suprir as necessidades dos alunos durante o maior período em 
que estes permanecem nas unidades de ensino, impondo consequentes alterações no planejamento e execução das refeições para as escolas integrantes do programa. Neste contexto, o presente estudo tem como objetivo avaliar a adequação da

\section{METODOLOGIA}

Trata-se de um estudo do tipo descritivo e transversal que foi realizado em uma escola de tempo integral do Município de Palmas, Tocantins, Brasil.

Primeiramente, apresentamos 0 projeto de pesquisa ao coordenador da alimentação escolar do município de Palmas e este indicou a escola que seria interessante realizar o estudo. Mediante sua aprovação, foi solicitado autorização do Secretário de Educação Municipal e da diretoria da escola para realização do projeto. Assim, depois das devidas autorizações foi enviado para a diretoria da unidade escolar, o Termo de Consentimento Livre e Esclarecido - TCLE para que ela assinasse, permitindo desta forma o uso do cardápio fornecido na escola e o acompanhamento da produção e distribuição das refeições. Este projeto foi submetido ao Comitê de Ética e alimentação fornecida por uma escola de tempo integral do município de Palmas, Tocantins, para diferentes faixas etárias, de acordo com as recomendações nutricionais do PNAE (BRASIL, 2013).

Pesquisa - CEP da Universidade Federal do Tocantins e aprovado conforme protocolo número 239/2013.

Para a coleta de dados, tivemos acesso ao cardápio do mês de novembro de 2013, fornecido pela Secretaria Municipal de Educação.

Foram realizadas visitas para acompanhamento e distribuição das três refeições diárias (café da manhã, almoço e lanche da tarde) na escola, por um período de dez dias, ou seja, duas semanas. Os dias foram escolhidos baseados no cardápio do dia, assim, foi possível avaliar o maior número de diferentes cardápios. Foram excluídos os cardápios dos dias de datas comemorativas.

Para avaliação da adequação da alimentação escolar, foi feita a pesagem de todas as preparações oferecidas no dia e pesados os alimentos separados após o preparo. 
Utilizamos uma balança analítica de precisão modelo Marte DL® $3.200 \mathrm{H}$ de 0,01gramas, com capacidade máxima para 3.200 gramas e mínima de 0,05 gramas. Desta forma, pôde nos proporcionar maior confiabilidade para verificar se a refeição estava sendo adequada e se seguia as recomendações preconizadas no PNAE. Além disso, todo o modo de preparo das 3 refeições foi acompanhado diariamente, no horário de 7:00 às 17:00h.

O cardápio escolar planejado, foi comparado com o oferecido e anotadas as mudanças que foram realizadas. $A$

\section{RESULTADOS}

Durante o período de dez dias de estudo, observou-se que apenas em um dia ( $\left.7^{\circ} \mathrm{dia}\right)$ houve o cumprimento total do cardápio elaborado pelo nutricionista da Secretária Municipal de Educação. Todos os outros dias observados apresentaram alterações nas preparações oferecidas aos alunos, desta forma, modificando 0 planejamento inicial (Tabela 01).

Após a realização da análise do cardápio executado, foi possível observar oferta de no mínimo três porções de frutas e hortaliças por adequação da alimentação fornecida foi avaliada através do software Avanutri®, sendo analisado os macronutrientes, micronutrientes (vitamina $A$, vitamina $C$, cálcio, ferro, zinco e magnésio) e fibras, conforme o tamanho das porções oferecidas aos estudantes segundo a faixa etária. Para análise dos resultados foram considerados os valores de referências de acordo com o PNAE (BRASIL, 2013). Utilizou-se o software Excel for Windows para digitação do banco de dados e cálculo da média, mediana, mínimo, máximo e desvio padrão.

semana nas refeições totalizando uma média de 328,6g/aluno/semana, atendendo assim as recomendações do PNAE (BRASIL, 2013).

Não houve oferta de bebidas com baixo valor nutricional, tais como refrigerantes e refrescos artificiais, bebidas ou concentrados à base de xarope de guaraná ou groselha, chás prontos para consumo e outras bebidas similares conforme recomenda o PNAE (BRASIL, 2013). Todos os sucos ofertados nos dez dias de cardápios 
eram provenientes de polpa de fruta congelada.

Alimentos enlatados, embutidos, doces, alimentos compostos (dois ou mais alimentos embalados separadamente para consumo conjunto), preparações semi-prontas ou prontas para consumo, ou alimentos concentrados (em pó ou desidratados para reconstituição) foram evitados no cardápio executado. O único alimento ofertado com essas características foi a salsicha (embutido), presente apenas no $9^{\circ}$ dia, que foi ofertado, sendo apenas uma vez neste período ( $\left.9^{\circ} \mathrm{dia}\right)$ (Tabela 01).

Tabela 01- Cardápios elaborados e executados de uma escola de tempo integral de Palmas, Tocantins, Brasil, 2014.

\begin{tabular}{|c|c|c|}
\hline $\begin{array}{l}\text { Dia da } \\
\text { Avaliação }\end{array}$ & Cardápio Elaborado & Cardápio Executado \\
\hline $1^{\circ}$ & $\begin{array}{l}\text { Desjejum: Leite Com Açúcar } \\
\text { Cuscuz de Milho } \\
\text { Almoço: Alface } \\
\text { Acém Cozido com Mandioca } \\
\text { Arroz Branco Cozido } \\
\text { Feijão Carioca Cozido } \\
\text { Farofa de Cenoura } \\
\text { Lanche da Tarde: Suco de Cajá com Açúcar } \\
\text { Biscoito Caseiro }\end{array}$ & $\begin{array}{l}\text { Desjejum: Leite Com Açúcar } \\
\text { Cuscuz de Milho } \\
\text { Almoço: Alface } \\
\text { Tomate } \\
\text { Acém Cozido com Batata } \\
\text { Arroz Branco Cozido } \\
\text { Feijão Carioca Cozido } \\
\text { Lanche da Tarde: Suco de Cajá com Açúcar } \\
\text { Biscoito Caseiro }\end{array}$ \\
\hline 2 은 & $\begin{array}{l}\text { Desjejum: Leite Achocolatado com Açúcar } \\
\text { Pão de Hot Dog } \\
\text { Mussarela } \\
\text { Almoço: Alface } \\
\text { Tomate } \\
\text { Bife de Fígado Bovino Acebolado } \\
\text { Arroz Cozido } \\
\text { Feijão Carioca Cozido } \\
\text { Maçã } \\
\text { Lanche da Tarde: Vitamina de Banana } \\
\text { Biscoito Doce }\end{array}$ & $\begin{array}{l}\text { Desjejum: Leite Achocolatado sem Açúcar } \\
\text { Pão de Hot Dog } \\
\text { Mussarela } \\
\text { Almoço: Alface } \\
\text { Tomate } \\
\text { Cenoura Cozida em Cubos } \\
\text { Bife de Fígado Bovino Acebolado } \\
\text { Arroz Cozido } \\
\text { Feijão Carioca Cozido } \\
\text { Lanche da Tarde: Vitamina de Banana } \\
\text { Biscoito Doce }\end{array}$ \\
\hline 3은 & $\begin{array}{l}\text { Desjejum: Leite Com Achocolatado e Açúcar } \\
\text { Bolo de Trigo } \\
\text { Almoço: Tomate } \\
\text { Repolho } \\
\text { Galinhada } \\
\text { Feijão Carioca Cozido } \\
\text { Melancia } \\
\text { Lanche da Tarde: Pão com Carne Moída } \\
\text { Suco de Acerola }\end{array}$ & $\begin{array}{l}\text { Desjejum: Leite com Achocolatado Sem } \\
\text { Açúcar } \\
\text { Bolo de Trigo } \\
\text { Almoço: Tomate } \\
\text { Repolho } \\
\text { Galinhada } \\
\text { Feijão Carioca Cozido } \\
\text { Melancia } \\
\text { Lanche: Pão com Carne Moída } \\
\text { Suco de Acerola } \\
\end{array}$ \\
\hline $4^{\circ}$ & $\begin{array}{l}\text { Desjejum: Leite Achocolatado com Açúcar } \\
\text { Pão de Queijo } \\
\text { Almoço: Alface } \\
\text { Estrogonofe de Carne } \\
\text { Arroz Branco Cozido } \\
\text { Feijão Carioca Cozido } \\
\text { Lanche: Suco de Cajá } \\
\text { Bolo de Milho }\end{array}$ & $\begin{array}{l}\text { Desjejum: Leite Achocolatado sem Açúcar } \\
\text { Pão de Queijo } \\
\text { Almoço: Alface } \\
\text { Estrogonofe de Carne } \\
\text { Arroz Branco Cozido } \\
\text { Feijão Carioca Cozido } \\
\text { Maçã } \\
\text { Lanche: Suco de Goiaba } \\
\text { Bolo de Trigo }\end{array}$ \\
\hline $5^{\circ}$ & $\begin{array}{l}\text { Desjejum: Suco de Acerola } \\
\text { Rosca de Coco } \\
\text { Almoço: Alface } \\
\text { Frango ao Molho Com Batata } \\
\text { Arroz Branco } \\
\end{array}$ & $\begin{array}{l}\text { Desjejum: Suco de Acerola } \\
\text { Pão Doce com Creme de Baunilha } \\
\text { Almoço: Alface } \\
\text { Frango Frito } \\
\text { Arroz }\end{array}$ \\
\hline
\end{tabular}




\begin{tabular}{|c|c|c|}
\hline & $\begin{array}{l}\text { Feijão Carioca } \\
\text { Lanche da Tarde: logurte } \\
\text { Enroladinho de Queijo }\end{array}$ & $\begin{array}{l}\text { Feijão Carioca } \\
\text { Purê de Batata } \\
\text { Lanche da Tarde: logurte } \\
\text { Enroladinho de Queijo }\end{array}$ \\
\hline $6^{\circ}$ & $\begin{array}{l}\text { Desjejum: Leite com Achocolatado e Açúcar } \\
\text { Pão Francês } \\
\text { Margarina } \\
\text { Almoço: Tomate } \\
\text { Acelga } \\
\text { Maria Isabel com Abóbora } \\
\text { Feijão Carioca } \\
\text { Lanche da Tarde: Vitamina de Banana } \\
\text { Biscoito Caseiro }\end{array}$ & $\begin{array}{l}\text { Desjejum: Leite com Achocolatado } \\
\text { Pão Francês } \\
\text { Margarina } \\
\text { Almoço: Alface } \\
\text { Tomate } \\
\text { Maria Isabel com Abóbora } \\
\text { Feijão Carioca } \\
\text { Lanche da Tarde: Vitamina de Banana } \\
\text { Biscoito Caseiro }\end{array}$ \\
\hline $7^{\circ}$ & $\begin{array}{l}\text { Desjejum: Leite com Açúcar } \\
\text { Cuscuz } \\
\text { Margarina } \\
\text { Almoço: Alface } \\
\text { Tomate } \\
\text { Beterraba } \\
\text { Bife Bovino } \\
\text { Arroz Branco } \\
\text { Feijão Carioca Cozido } \\
\text { Melancia } \\
\text { Lanche da Tarde: Suco de Maracujá } \\
\text { Bolacha Água e Sal }\end{array}$ & $\begin{array}{l}\text { Desjejum: Leite com Açúcar } \\
\text { Cuscuz } \\
\text { Margarina } \\
\text { Almoço: Alface } \\
\text { Tomate } \\
\text { Beterraba } \\
\text { Bife Bovino } \\
\text { Arroz Branco } \\
\text { Feijão Carioca } \\
\text { Melancia } \\
\text { Lanche da Tarde: Suco de Maracujá } \\
\text { Bolacha Água e Sal }\end{array}$ \\
\hline $8^{\circ}$ & $\begin{array}{l}\text { Desjejum: Leite Integral } \\
\text { Café com Açúcar } \\
\text { Rosca de Coco } \\
\text { Almoço: Alface } \\
\text { Beterraba } \\
\text { Bife Bovino Grelhado } \\
\text { Arroz com Cenoura } \\
\text { Feijão Carioca } \\
\text { Melancia } \\
\text { Lanche da Tarde: Leite com Achocolatado } \\
\text { Bolo de Milho }\end{array}$ & $\begin{array}{l}\text { Desjejum: Leite Integral } \\
\text { Café com Açúcar } \\
\text { Pão Doce } \\
\text { Almoço: Alface } \\
\text { Tomate } \\
\text { Carne Bovina Cozida Com Batata } \\
\text { Arroz Branco } \\
\text { Feijão Carioca } \\
\text { Farofa de Cenoura } \\
\text { Lanche da Tarde: Suco de Cajá com Açúcar } \\
\text { Pão Doce }\end{array}$ \\
\hline 9응 & $\begin{array}{l}\text { Desjejum: Leite com Achocolatado } \\
\text { Bolo de Trigo } \\
\text { Almoço: Couve Refogado } \\
\text { Frango Assado } \\
\text { Arroz } \\
\text { Feijão Carioca } \\
\text { Creme de Milho } \\
\text { Lanche da Tarde: Leite com Achocolatado } \\
\text { Enroladinho de Queijo }\end{array}$ & $\begin{array}{l}\text { Desjejum: Leite dom Achocolatado } \\
\text { Bolo de Trigo } \\
\text { Almoço: Couve Refogada } \\
\text { Tomate } \\
\text { Peito de Frango Frito } \\
\text { Arroz Branco } \\
\text { Feijão Carioca } \\
\text { Creme de Milho } \\
\text { Lanche da Tarde: Leite com Achocolatado } \\
\text { Enroladinho de Salsicha }\end{array}$ \\
\hline $10^{\circ}$ & $\begin{array}{l}\text { Desjejum: Leite com Achocolatado } \\
\text { Pão de Queijo } \\
\text { Almoço: Feijoada } \\
\text { Arroz } \\
\text { Farofa de Couve } \\
\text { Laranja } \\
\text { Lanche da Tarde: logurte } \\
\text { Rosca }\end{array}$ & $\begin{array}{l}\text { Desjejum: Leite com Achocolatado } \\
\text { Pão de Queijo } \\
\text { Almoço: Couve Crua } \\
\text { Feijoada } \\
\text { Arroz Branco } \\
\text { Laranja } \\
\text { Lanche da Tarde: Suco de Acerola com } \\
\text { Açúcar } \\
\text { Pão Doce }\end{array}$ \\
\hline
\end{tabular}

Constatou-se que o valor médio de Vitamina A e $\mathrm{C}$ estavam adequados para todas as idades. Entretanto, 0 cálcio e o magnésio não atenderam a recomendação para nenhuma das faixas etárias estudadas. O ferro adequou-se para as idades de 6-10 e 11-15 anos e o zinco apenas para 6-10 anos. As fibras apresentaram menor valor médio de adequação (47,6\%) Rev. Cereus, v. 9, n. 2, p.92-107, mai-ago./2017, UnirG, Gurupi, TO, Brasil. 
para todas as faixas etárias (Tabela 02).

Com relação aos macronutrientes, observou-se que o valor médio de carboidratos ofertados no cardápio atingiu o recomendado pelo PNAE para a faixa etária de 6-10 e para as idades de 11-15 e 16-18 anos foi insuficiente. Já o lipídeo esteve abaixo dos valores recomendados para todos os grupos etários. Em relação à proteína, adequou-se apenas para a faixa etária de 6-10 anos, com média a 36,7g/dia (Tabela 02). É importante frisar que houve adequação de energia unicamente para a faixa etária de 6-10 anos, em contrapartida, para os alunos de 11-15 e 16-18 anos foi observado adequação de apenas $73 \%$ e $64 \%$, respectivamente, em relação às recomendações do PNAE.

Tabela 02 - Distribuição percentual dos valores recomendados para o consumo alimentar e as quantidades disponibilizadas para consumo por uma escola de tempo integral de Palmas, Tocantins, Brasil.

\begin{tabular}{|c|c|c|c|c|c|c|c|}
\hline \multicolumn{4}{|c|}{ RDA (70\% como exigido pelo PNAE) } & \multicolumn{4}{|l|}{ \% de adequação } \\
\hline \multirow[t]{2}{*}{ Nutriente } & \multicolumn{3}{|c|}{ Faixa Etária (anos) } & \multirow[t]{2}{*}{ Nutriente } & \multicolumn{3}{|c|}{ Faixa Etária (anos) } \\
\hline & $06-10$ & $11-15$ & $16-18$ & & $06-10$ & $11-15$ & $16-18$ \\
\hline Energia (kcal) & 1000 & 1500 & 1700 & Energia & 109,7 & 73 & 64 \\
\hline Carboidrato (g) & 162,5 & 243,8 & 276,3 & Carboidrato (g) & 112,6 & 75 & 66,8 \\
\hline Proteína (g) & 31,2 & 46,9 & 50 & Proteína (g) & 117,6 & 78,2 & 73,5 \\
\hline Lipídeo (g) & 25 & 37,5 & 42,5 & Lipídeo (g) & 96,8 & 64,5 & 57 \\
\hline Vit. A ( $\mu \mathrm{g})$ & 350 & 490 & 560 & Vit. A $(\mu \mathrm{g})$ & 337,5 & 241 & 210 \\
\hline Vit. C (mg) & 26 & 42 & 49 & Vit. C (mg) & 201,5 & 124,7 & 107 \\
\hline Cálcio (mg) & 735 & 910 & 910 & Cálcio (mg) & 54,43 & 42,3 & 42,3 \\
\hline Ferro (mg) & 6,3 & 7,5 & 9,1 & Ferro (mg) & 126,9 & 106,6 & 88,1 \\
\hline Magnésio (mg) & 131 & 222 & 271 & Magnésio (mg) & 82,7 & 48,8 & 40 \\
\hline Zinco (mg) & 4,7 & 6,3 & 7 & Zinco (mg) & 110,6 & 82,5 & 74,7 \\
\hline Fibras (g) & 18,7 & 21,1 & 22,4 & Fibras (g) & 52,4 & 46,4 & 44 \\
\hline
\end{tabular}

Fonte: Energia- Organização das Nações Unidas para Agricultura e Alimentação (FAO), 2001; Carboidrato, Proteína e Lipídeo- Organização Mundial de Saúde (OMS), 2003; Fibras, Vitaminas e Minerais- Referência da Ingestão Dietética (DRI)/ Instituto de Medicina Americano (IOM), 1997-2000- 20001. Adaptada.

\section{DISCUSSÃO}

O nutricionista tem papel importante na definição do cardápio escolar, orientando a escolha dos alimentos que devem fazer parte da alimentação dos alunos e avaliando a qualidade dos gêneros utilizados. A presença do nutricionista habilitado no âmbito do PNAE é uma das garantias da qualidade da alimentação escolar, sobretudo quando se considera que 0 
programa visa atender às necessidades nutricionais dos alunos e contribui para a melhoria da saúde da população (BRASIL, 2013).

De acordo com Costa, Lima \& Ribeiro (2002) as merendeiras juntamente com o nutricionista têm sob sua responsabilidade a tarefa de compreender todo o processo de produção da refeição e o caráter social do PNAE, o que vai conferir sentido aos seus trabalhos. No entanto, na confecção diária das refeições, a ausência de um nutricionista faz com que as merendeiras decidam, os tipos de alimentos e a sua forma de preparo, o que gera como consequência a não adequação dos macro e micronutrientes exigidos pelo PNAE (BRASIL, 2013).

Foi observado que no momento da preparação das refeições, que quando não havia todos os ingredientes necessários, estes eram substituídos por outros produtos disponíveis, resultando na inadequação de alguns nutrientes importantes. Esse fato acorreu algumas vezes, pois os fornecedores não entregavam a tempo de realizar a preparação.

Importante destacar também que, os carboidratos e as proteínas adequaram-se apenas para a faixa etária de 6-10 anos e o lipídeo a nenhuma das faixas etárias. Sabe-se que as fontes de energia devem estar equilibradas entre carboidratos e lipídios. Os carboidratos são necessário para evitar 0 desenvolvimento de cetose e hipoglicemia, assim como de lipídios para prevenir deficiência de ácido linoleico (HEIRD, 1999). Cada macronutriente ao ser absorvido pelo organismo tem finalidades específicas. Assim, a proteína será utilizada na formação e reparação de células, o carboidrato e o lipídio serão utilizados para 0 fornecimento de energia imediata e armazenamento do restante, como glicogênio e tecido adiposo, respectivamente (MAHAN et al, 2000).

Em relação ao teor de vitamina A, dos dez dias analisados, ultrapassou a recomendação do PNAE em média $69 \%$, entretanto, não atingiu a Tolerable Upper Intake Level (UL) para todas as faixas. Este resultado corrobora com o estudo realizado por SILVA \& GREGÓRIO (2012), que avaliou a composição nutricional dos cardápios da alimentação escolar das escolas da rede municipal de Taquaraçu de Minas - MG, onde observaram que os valores de vitamina A estavam acima do recomendado. 
Dentre as múltiplas funções, a vitamina A contribui para o desenvolvimento tecidual e, juntamente com o ferro, favorece a eritropoiese, dificultando o aparecimento da anemia, muito comum nesta fase da vida (ABRANCHES et al, 2009) .

A vitamina $C$ alcançou em média $144,4 \%$ da adequação. Esse resultado é importante, pois segundo TANAKA (2007) as manifestações do excesso de vitamina C causam diarréia, podendo ocasionar ainda náuseas, vômitos, aumento da absorção do ferro que podem causar problemas potenciais ao rim e a bexiga em razão do aumento da sua excreção, uma vez que o ácido ascórbico é parcialmente convertido em ácido oxálitico, podendo com isso induzir à litíase oxálica.

O ferro chegou a ultrapassar cerca de $80 \%$ da recomendação da RDA para as faixas etárias de 6-10 e 11-15anos, entretanto, não ultrapassou o valor da UL. Para 16-18 anos este nutriente apresentou $88 \%$ de adequação. Este resultado vai ao encontro dos achados por CARVAJAL et al (2009), que em ambos os estudos, o percentual de ferro foi superior ao recomendado pelo PNAE. É importante frisar que as reservas de ferro no organismo devem permanecer dentro de limites estreitos, pois se por um lado a sua queda provoca diminuição da imunidade celular e humoral com o conseqüente aumento da incidência e da gravidade das infecções, por outro, o seu aumento provoca os mesmos efeitos, por outros mecanismos (SILVA, 1998; JUNIOR, 2014).

PEREIRA NETO (2007) enfatiza que a biodisponibilidade de ferro depende da sua forma química e da presença de fatores inibidores, como é - caso do cálcio, que diminui a absorção desse mineral, ou favorecedores como a vitamina $\mathrm{C}$ que aumenta sua absorção. Considerando a complexidade da composição da refeição, a interação nutriente-nutriente e a falta de estudos de biodisponibilidade em longo prazo, torna-se difícil estabelecer a quantidade real de ferro alimentar absorvida pelas crianças e adolescentes.

Dentre os dias analisados, apenas no $9^{\circ}$ dia, o cálcio foi adequado para todas as faixas etárias. Isto só foi possível, pois neste dia foi oferecido leite, no desjejum e lanche da tarde, além de ter sido usado ainda em preparações oferecidas no almoço. Entretanto, como o cálcio é um inibidor da absorção do ferro nos alimentos, 
não é recomendado que ele seja oferecido nas refeições principais (almoço e jantar). Porém, nenhum dos outros dias o cálcio atendeu a recomendação, apresentando cerca de $50 \%$ apenas de adequação. Sendo assim, é necessário que o cardápio oferecido no desjejum e lanche da tarde seja acrescido de fontes de cálcio para atender a recomendação, com baixa intervenção na absorção de outros micronutrientes.

As recomendações nutricionais de cálcio variam durante a vida dos indivíduos, com maiores necessidades durante períodos de rápido crescimento, como na infância (SBP, 2008). Uma vez que o aporte deste mineral esteja inadequado, respostas negativas podem incidir no desenvolvimento de crianças, principalmente no período de estirão de crescimento, que virá ocorrer posteriormente, durante a adolescência (ABRANCHES et al, 2009).

Foi observado por ABRANCHES et al (2009) ao avaliarem a adequação alimentar de creches pública e privada no contexto do programa nacional de alimentação escolar, que os alimentos consumidos não atingiam os valores nutricionais recomendados, sendo 0 cálcio um dos nutrientes mais deficientes no cardápio.

O magnésio ofertado nas refeições analisadas não foi suficiente para nenhuma das faixas etárias estudadas. O magnésio desempenha papel de grande relevância orgânica, participando de uma série de reações que incluem o metabolismo glicídico, lipídico, protéico e de ácidos nucléicos. A ingestão de quantidades adequadas de cálcio e magnésio em crianças com idade escolar é fundamental, pois esses micronutrientes diminuem o risco de doenças crônicas, como osteoporose e hipertensão arterial na idade adulta (MOREIRA et al, 2014).

A fibra alimentar também não se adequou em nenhum dos dias analisados para nenhuma faixa etária, ficando em média 31,3\% abaixo do recomendado pelo PNAE (BRASIL, 2013). Além disso, foi a variável alimentar que mais apresentou inadequação, não chegando a $55 \%$ para nenhuma faixa etária. Apesar de ter sido ofertada a quantidade de frutas e verduras preconizadas pelo PNAE (200g/aluno/semana) as porções oferecidas não foram suficientes para a recomendação de fibras, sendo necessário o aumento da porção de frutas e verduras ou outras opções 
como, cereais integrais, que são boas fontes de fibras alimentares. $O$ consumo adequado de fibras para crianças, assim como para adultos, proporciona o funcionamento normal do intestino, previne câncer relacionado à dieta, diminui a concentração sérica de colesterol, reduz o risco de doença cardiovascular e ajuda na prevenção da obesidade (VIEIRA et al, 2008).

A quantidade de zinco ofertada nas refeições analisadas não foi suficiente para as faixas etárias de 1115 e 16-18 anos. Entre os efeitos da deficiência de zinco se destaca a redução da função imune e prejuízo para o crescimento durante a infância e a adolescência (TORAL et al, 2014). Este resultado torna forte o estudo realizado por SILVA \& GREGÓRIO (2012) onde observaram que o zinco foi suficiente para alunos entre 6-10 anos.

Os resultados observados neste estudo são consequência do tamanho das porções dos alimentos que são distribuídas na escola, onde não há diferenciação por faixa etária, ou seja, a mesma porção que é fornecida para um criança de 6 anos é igual para um adolescente de 18 anos.

Neste estudo foi possível observar que os cardápios oferecidos atingem, em sua maioria, as recomendações do PNAE para alunos de 6-10 anos de idade e são parcialmente insuficientes para as faixas etárias de 11-15 e 16-18 anos, nos fazendo compreender que quanto maior a idade, menor é a porcentagem de adequação de todos os macronutrientes e micronutrientes estudados. O ideal é que haja diferenciação das porções distribuídas aos alunos, tendo por base as diferentes necessidades das crianças e adolescentes. Somente desta forma, será possível atender a recomendação atual do PNAE e oferecer as nossas crianças e adolescentes uma alimentação de qualidade e de melhor valor nutricional.

Como limitação deste estudo, podemos destacar o número reduzido de dias de acompanhamento do cardápio da escola, o que não permite avaliar a gravidade da inadequação de nutrientes conforme os grupos etários. Além disso, não foi controlado a alimentação da criança em casa, e, portanto, não é possível afirma que o grupo estudado apresenta carência nutricional. 


\section{CONSIDERAÇÕES FINAIS}

Os resultados deste estudo evidenciam a necessidade de ajustes nos cardápios, com vista ao cumprimento das metas do PNAE para escola de tempo integral. Observou-se ingestão deficiente de energia e de alguns micronutrientes, especialmente vitaminas, fibras e alguns minerais, que podem prejudicar o desenvolvimento e crescimento durante a adolescência. A inadequação da disponibilidade da maioria dos micronutrientes encontrada na escola sugere a necessidade de observância quanto à alimentação ofertada.

Reforça-se a importância da educação nutricional, elaboração de cardápios mais variados e seu cumprimento integral, garantindo a adequação qualitativa e quantitativa da alimentação ofertada em conforme estabelece o PNAE.

\section{REFERÊNCIAS}

ABRANCHES MV, PAULA HAA, MATA GMSC, SALVADOR BC, MARINHO MS, PRIORE SE. Avaliação da adequação alimentar de creches pública e privada no contexto do programa nacional de alimentação escolar. Revista Nutrire, São Paulo, SP 2009; 34(2): 43-57.

BRASIL, Ministério da Educação. Manual de orientação para a alimentação escolar na educação infantil, ensino fundamental, ensino médio e na educação de jovens e adultos. Brasília: FNDE; 2012. 23 p.

Brasil. Ministério da Educação. Fundo nacional de desenvolvimento da educação. Resolução $\mathrm{n}^{\circ} 26$ de 17 de junho de 2013. Dispõe sobre o atendimento da alimentação escolar aos alunos da educação básica no âmbito do Programa Nacional de Alimentação Escolar - PNAE. [acesso 2013 out 27]. Disponível em: http://www.fnde.gov.br/programas/alimentacao-escolar.

CARVAJAL AESS, KOEHNLEIN EA, BENNEMANN RM. Avaliação da merenda de uma Escola Municipal de $1^{\underline{a}}$ a $4^{\underline{a}}$ série de Maringá - PR. VI EPCC Encontro Internacional de Produção Científica Cesumar. Maringá: Centro Universitário de Maringá, 2009.

COSTA EQ, LIMA ES, RIBEIRO VMB. O treinamento de merendeiras: análise do material instrucional do Instituto de Nutrição Annes Dias Rio de Janeiro (1956-94). História, Ciências, Saúde. Manguinhos, Rio de Janeiro, 2002;9(3):535-60. 
DANELON MAS, DANELON MS, SILVA MV. Serviços de alimentação destinados ao público escolar: análise da convivência do Programa de Alimentação Escolar e das cantinas. Segurança Alimentar e Nutricional, Campinas, 2006, 13(1): 85-94.

HEIRD WC: From Nutrition Requirements During Infancy. In: Modern Nutrition in Health and Disease. Ninth Edition Edited by: Shils ME, Olson JA, ShikeM,Ross AC. Baltimore, USA. Williams and Wiliams; 1999:839-843.

JUNIOR JF. O excesso de ferro aumenta a incidência de câncer, de infarto do miocárdio e de infecções de repetição. Associação Brasileira de Medicina Complementar. [Acesso em 2014 Fev 17] Disponível em: <http://www.medicinacomplementar.com.br/biblioteca_doencas_excesso_ferro.asp>.

LEÃO LS, ARAÚJO LM, MORAES LT, ASSIS AM. Prevalência de obesidade em escolares de Salvador, Bahia. Arquivos Brasileiros de Endocrinologia e Metabologia 2003;47:151-7.

MAHAN LK, ESCOTT-STUMP, S. KRAUSE. Alimentos, nutrição e dietoterapia. 9. ed.São Paulo: Roca, 2000. 179 p.

MENEGAZZO M, FRACALOSSI K, FERNADES AC, MEDEIROS NI. Avaliação qualitativa das preparações do cardápio de centros de educação infantil. Revista de Nutrição, Campinas, 2011, 24(2):243-51.

MOREIRA TR, PRASS FS, BLASI TC. Estudo comparativo do estado nutricional de crianças em idade escolar matriculadas em escola pública e privada do município de Santa Maria - RS. [Acesso em 2014 Fev 17] Disponível em: <http://www.nutricaoativa.com.br/arquivos/artigo3.pdf>.

NETO PM, REZENDE FAC, ROSADO GP, FOSADO LEFPL, FRANCESCHINI SCC. Importância do ferro na infância. Nutrição Brasil, 2007; 6(2):111-6.

PÉREZ-CUETO FJA, ALMANZA-LÓPEZ MJ, PÉREZ-CUETO JD, EULERT ME. Estado nutricional y características de la dieta de un grupo de adolescentes de lalocalidad rural de Calama, Bolívia. Nutricion Hospitalaria. 2009;24(1):46-50.

SILVA MMDCS, GREGÓRIO EL. Avaliação da composição nutricional dos cardápios da alimentação escolar das escolas da rede municipal de Taquaruçu de Minas - MG. HU-Revista, Juiz de Fora, 2012; 37(3): 387-94.

SILVA MV. Alimentação na escola como forma de atender às recomendações nutricionais de alunos dos Centros Integrados de Educação Pública (CIEPS). Caderno de Saúde Pública, Rio de Janeiro, 1998, 14(1):171-80. 
SIQUEIRA PP, ALVES JGB, FIGUEIROA JN. Fatores associados ao excesso de peso em crianças de uma favela do Nordeste brasileiro. Revista Paulista de Pediatria 2009;27(3):251-7.

SOCIEDADE BRASILEIRA DE PEDIATRIA. Manual de orientação: obesidade na infância e adolescência. São Paulo: SBP; 2008 [acesso 2013 out 24]. Disponível em:http://www.sbp.com.br/PDFs/Man\%20Nutrologia_Obsidade.pdf.

TANAKA DL. Influência da desidratação por spray drying sobre o teor ácido ascórbico no suco de acerola (malpighiassp)[dissertação]. Araraquara, SP; 2007.

TORAL N, RHEIN SO, CINTRA IP, FISBERG M. O papel do zinco na infância e adolescência. [Acesso em 2014 Fev 17] Disponível em: http://www.moreirajr.com.br/revistas.asp?fase=r003\&id_materia=3057.

VIEIRA MNCM, JAPUR CC, RESENDE CMM, MONTEIRO JP. Valores de referência de ingestão de nutrientes para avaliação e planejamento de dietas de crianças de um a oito anos. Revista Faculdade de Medicina, Ribeirão Preto, 2008; 41 (1): 67-76.

Recebido em: 11/10/2016

Aprovado em: 28/08/2017 